\title{
Ein neues Image der Schweiz ? Ergebnisse einer Umfrage über das Urteil der Schweizer bezüglich der Entwicklungszusammenarbeit
}

Une nouvelle image de la Suisse? Les résultats d'une enquête sur le jugement des suisses à l'égard de la Coopération au développement

\section{Gilbert Rist}

\section{OpenEdition}

Journals

\section{Electronic version}

URL: http://journals.openedition.org/sjep/1002

DOI: $10.4000 /$ sjep.1002

ISSN: 1663-9677

Publisher

Institut de hautes études internationales et du développement

\section{Printed version}

Date of publication: 1 janvier 1984

Number of pages: 155-158

ISSN: 1660-5926

Electronic reference

Gilbert Rist, « Ein neues Image der Schweiz ? Ergebnisse einer Umfrage über das Urteil der Schweizer bezüglich der Entwicklungszusammenarbeit », Schweizerisches Jahrbuch für Entwicklungspolitik

[Online], 4 | 1984, Online erschienen am: 03 Februar 2013, abgerufen am 08 September 2020. URL http://journals.openedition.org/sjep/1002 ; DOI : https://doi.org/10.4000/sjep.1002

This text was automatically generated on 8 septembre 2020

(c) The Graduate Institute 


\section{Ein neues Image der Schweiz? Ergebnisse einer Umfrage über das Urteil der Schweizer bezüglich der Entwicklungszusammenarbeit}

Une nouvelle image de la Suisse? Les résultats d'une enquête sur le jugement des suisses à l'égard de la Coopération au développement

Gilbert Rist

\section{EDITOR'S NOTE}

Zusammenfassung auf Deutsch. Volltext auf Französisch in Annuaire suisse de politique de développement: „Une nouvelle image de la Suisse ? Les résultats d'une enquête sur le jugement des suisses à l'égard de la Coopération au développement", http:// aspd.revues.org/1167.

\section{ABSTRACTS}

Eine von Isopublic vor kurzem durchgeführte Untersuchung gibt Auskunft über die Art und Weise, wie die Schweizer die Entwicklungshilfe rechtfertigen und wie sich diese ihrer Meinung nach entwickeln soll. Diese Studie lässt die Originalität der Haltung der Tessiner hervortreten, welche über die Probleme der Dritten Welt am besten informiert und gleich zeitig am meisten engagiert sind. Im Gegensatz dazu machen sich die Westschweizer am wenigsten Illusionen über 
die Möglichkeiten wirksamer Eingriffe. Im grossen und ganzen stehen die Schweizer den Aktionen internationaler Solidarität sehr aufgeschlossen gegenüber, doch stellen sie sich diese Solidarität eher karitativ als strukturell vor. 